\title{
Espaços claustrofóbicos na obra de Lourenço Mutarelli
}

Pascoal Farinaccio ${ }^{1}$

Em seu livro O Tempo e o cão, cujo subtítulo é "a atualidade das depressões", a psicanalista Maria Rita Kehl analisa o mal-estar na cultura contemporânea discutindo o fenômeno atual e alarmante do aumento dos diagnósticos de depressão. Vale a pena citar alguns números: "Só nos Estados Unidos, estima-se que 3\% da população sofra de depressão crônica, ou seja, cerca de 19 milhões de pessoas, das quais 2 milhões de crianças. No Brasil, cerca de 17 milhões de pessoas foram diagnosticadas como depressivas nos primeiros anos do século XXI". E, de acordo com estudos divulgados pela Organização Mundial da Saúde, os casos tendem a aumentar: "Até 2020, segundo a OMS, a depressão terá se tornado a segunda principal causa de morbidade no mundo industrializado, atrás apenas de doenças cardiovasculares" (Kehl, 2009, p. 50-51).

Um dado curioso a respeito desses números é que eles indicam um aumento dos quadros mórbidos de depressão justamente em "uma sociedade que parece essencialmente antidepressiva, tanto no que se refere à promoção de estilos de vida e ideias ligados ao prazer, à alegria e ao cultivo da saúde quanto à oferta de novos medicamentos para o combate das depressões" (Kehl, 2009, p. 51). Levando-se em conta essa perspectiva, pode-se estudar a depressão, conforme propõe a autora, como um "sintoma social", considerando os depressivos, "em seu silêncio e recolhimento", como um "grupo tão incômodo e ruidoso quanto foram as histéricas no século XIX". Assim sendo, a "depressão é a expressão de mal-estar que faz água e ameaça afundar a nau dos bem-adaptados ao século da velocidade, da euforia prêt-à-porter, da saúde, do exibicionismo e, como já se tornou chavão, do consumo generalizado" (Kehl, 2009, p. 22).

Pode-se pensar a doença, nesses termos, como um dispositivo teórico-crítico que faz falar determinações profundas da suposta "saúde" social. Com efeito, de que sociedade se trata? Maria Rita Kehl elenca algumas características básicas que valem ser lembradas aqui para proveito de nossa análise das personagens fracassadas de Lourenço Mutarelli. Uma das características da sociedade contemporânea é a "paixão pela segurança", um desejo contínuo de alcançar o bem-estar em todas as esferas de atuação social e afetiva,

\footnotetext{
${ }^{1}$ Doutor em teoria e história literária, professor de literatura brasileira na Universidade Federal Fluminense (UFF), Niterói, RJ, Brasil. E-mail: pascoalf@hotmail.com
} 
de tal modo que chega a se tornar insuportável a simples ideia de que "a vida seja um percurso pontuado por riscos inevitáveis" (Kehl, 2009, p. 56). No caso, todo e qualquer fracasso, seja no trabalho, seja na vida afetiva, é motivo de escândalo. Numa sociedade desse tipo, em que "o importante é ganhar, não competir" gera-se o primado de um ressentimento contínuo, já que seus "membros se colocam, antes de mais nada, como demandantes de reconhecimento por parte do Outro" (Kehl, 2009, p. 98-99). Com um pouco de malícia, digamos que se trata de uma sociedade em que todos, sem exceção, querem aparecer bem na foto - o que nem sempre é possível.

A alusão à fotografia não é aqui de modo algum casual, já que o universo da imagem é parte estruturante da atual sociedade do consumo. Como afirma Kehl, os sujeitos contemporâneos são "ávidos pelo consumo de imagens que lhes indiquem quem eles são". A identidade pessoal depende do consumo das imagens - elas nos dão à representação na sociedade do consumo. "Pois o que distingue a sociedade de consumo não é o fato de que todos comprem incessantemente os bens em oferta, acessíveis a poucos, mas que todos estejam de acordo com a ideia de que tanto o sentido da vida social como o valor dos sujeitos sejam dados pelo consumo" (Kehl, 2009, p. 100). É uma sociedade, portanto, que postula o consumo (e o imaginário do gozo a ele associado) como o "verdadeiro organizador do laço social" (Kehl, 2009, p. 100), que não admite fracassos, que aposta todas as fichas na competitividade desenfreada, e que, por isso mesmo, tende a gerar nos indivíduos frustrações e ressentimentos de toda ordem.

Por fim, mas não menos importante (em verdade, trata-se justamente da principal linha de análise de Kehl), há a "brutalidade das relações dos sujeitos contemporâneos com o tempo" (Kehl, 2009, p. 17): uma experiência com o tempo que, nos dias atuais, resume-se essencialmente à "experiência da velocidade". A aceleração é imposta aos mínimos atos cotidianos. E difunde-se por toda parte com a hegemonia dos computadores e da internet, a qual queremos cada vez mais e mais rápida. Nessa perspectiva, o depressivo pode ser compreendido como aquele que está perdendo a corrida em que todos se empenham. Daí "sua lentidão, tão incompreensível e irritante para os que convivem com ele" (Kehl, 2009, p. 18).

Com tantos motivos para ser feliz na sociedade do consumo e das maravilhas tecnológicas, o depressivo perde tempo no desfrute dos bens disponíveis. Perde a corrida rumo ao gozo (há sempre alguém gozando mais que ele, acima dele, hierarquicamente), perde tempo, é um perdedor. Como o são a maioria das personagens de Lourenço Mutarelli. Sempre um pouco depressivas, humilhadas, parecem carregar todo o peso do mundo em suas costas. Nos exemplos que iremos abordar, na esperança 
de se protegerem buscam refúgio em lugares fechados, muitas vezes um simples quarto que possa servir como um útero materno, uma proteção contra o mundo exterior. Mas são tentativas que sempre redundam em fracasso, as quatro paredes em fim de contas compondo um espaço claustrofóbico. Também nesses lugares fechados não encontram a proteção desejada. Também neles pesa sobre essas personagens a consciência de estarem perdendo a corrida coletiva dos que, de uma maneira ou outra, conseguiram se adaptar ao atual estágio da sociedade.

Essas personagens de Mutarelli, a exemplo dos depressivos (e muitas delas sofrem, de fato, de vários tipos de doença psíquica) colocam em evidência a brutalidade da sociedade contemporânea em suas exigências de rentabilidade, sucesso a todo custo, energia e velocidade nas ações etc. São anti-heróis, conforme definidos e estudados por Victor Brombert: "personagens fracos, incompetentes, dessorados, humilhados, inseguros, ineptos, às vezes abjetos - quase sempre atacados de envergonhada e paralisante ironia". Esse modo anti-heroico de comportamento implica a "presença negativa do modelo subvertido ou ausente", ou seja, ao contraporem-se radicalmente aos heróis e demais vencedores, essas personagens "lançam dúvidas sobre valores que vêm sendo aceitos ou que foram julgados inabaláveis" (Brombert, 2001, p. 14).

As personagens de Mutarelli geralmente vivem nos subúrbios de São Paulo, em apartamentos pequenos e com mobília reduzida ao mínimo indispensável. Chama a atenção que histórias inteiras se passem tendo como único cenário quartos fechados, tal como ocorre nos romances Jesus Kid e O natimorto. Mas também nos romances $O$ cheiro do ralo e $A$ arte de produzir efeito sem causa o espaço fechado é um cenário básico, onde muitos acidentes da trama se desenrolam. E podem-se juntar a isso as inúmeras referências a cofres, caixas, gavetas, lugares também fechados, que têm a ver com a intimidade e com as memórias pessoais (guardamos em cofres e gavetas papéis e objetos de importância íntima). Longe de pretender aqui uma análise minuciosa desses romances, o que nos levaria a ultrapassar os propósitos deste ensaio, faremos a seguir uma série de referências breves às obras em questão, levando em conta o espaço em que os fatos narrados acontecem. A finalidade disso é mostrar a forte conexão entre os problemas psicológicos das personagens e o espaço por elas ocupado. Considerando que há uma progressão nesse enlace entre estados psicológicos e espaços fechados (uma maior perturbação mental em espaços cada vez mais fechados e claustrofóbicos...), começaremos com $O$ cheiro do ralo, passando depois pelo $A$ arte de produzir efeito sem causa, Jesus Kid e finalizando com $O$ natimorto, ponto extremo desse tipo de relação sensível entre estados de alma e espaço físico. 
A história de $O$ cheiro do ralo se passa numa loja de compra e venda de objetos usados. A personagem principal recebe em sua loja uma série de clientes, em geral endividados, que tentam lhe vender todo tipo de quinquilharias. O seu procedimento básico é negociar com esses clientes, sempre buscando comprar os objetos pelo menor preço possível. Há no protagonista um desejo perverso de humilhar esses clientes, às vezes ironizando o suposto valor que eles atribuem a seus pertencentes, outras simplesmente mandando-as embora quando trazem objetos pesados. Estabelece-se um jogo pervertido de poder, que tem como base de apoio a superioridade financeira do protagonista em relação a esses pobres coitados.

No espaço fechado da loja o protagonista, que jamais recebe um nome ao longo da obra, coleciona objetos sobre objetos. Aliás, não só não recebe um nome próprio, como também de sua história pregressa nada sabemos. É uma personagem plana nesse sentido, sem a profundidade que poderia resultar de uma história pessoal rica em acontecimentos. Sua relação obsessiva de aquisição de objetos parece justamente responder a esse vazio, pois é recorrente que seus clientes lhe digam que os objetos que trazem para vender "têm muitas histórias". É nítido o desejo desse protagonista de incorporar tais histórias à sua história pessoal, conferindo-lhe assim algum sentido e coerência. O ponto culminante desse procedimento é o episódio em que tenta montar o seu próprio pai por meio da montagem de objetos adquiridos - um olho de vidro, uma perna mecânica - inventando assim uma origem familiar que lhe escapa. Sem nunca ter conhecido o pai, o protagonista tenta criá-lo, nomeá-lo, numa operação de bricolage de objetos de origens diversas que passam a funcionar em novo contexto como um "pai Frankenstein".

Em A poética do espaço, Bachelard empreende o que chama de uma topoanálise, um estudo psicológico sistemático dos locais de nossa vida íntima, tomando a casa, por exemplo, como "um instrumento de análise para a alma humana" (Bachelard, 1993, p. 20). Trata-se de estudo que pode render muito para a análise que temos tentado dos espaços claustrofóbicos representados nos romances de Lourenço Mutarelli. Bachelard entende a casa como espaço por excelência da intimidade: "A casa, mais do que a paisagem, é um 'estado de alma'. Mesmo reproduzida em seu aspecto exterior, ela fala de uma intimidade" (Bachelard, 1993, p. 84). No caso de O cheiro do ralo, pode-se tomar a loja do protagonista como sua "casa", pois é ali que ele passa a maior parte do tempo e vive suas relações econômicas, mais ou menos sádicas, mas também as afetivas. Acima de tudo, é na loja que de certa forma ele busca refúgio, procura salvar-se de sua própria solidão e desamparo. A sua casa, rigorosamente falando, tem papel apagado na economia do romance. 
Pensando-se a loja como um estado da alma, evidencia-se o cheiro maligno que dela exala. Há um banheirinho na loja cujo ralo fede, e o cheiro nauseabundo por assim dizer infesta todo o romance; nota-se inclusive um aumento do cheiro ruim, que é progressivamente proporcional à perda de razão e ao acirramento das obsessões depravadas do protagonista. O protagonista vê características diabólicas no ralo: "Porque na idade média o cu representava o inferno. É isso. Eu sei que é. E o ralo é o cu do mundo". Amparado nessa linha de raciocínio, atribui ao ralo o motivo de estar se sentindo cada vez mais doente: "É isso. De tanto inalar merda meu cérebro se confundiu [...]. É a porra do cheiro. Isso que está me deixando cansado. Doente, talvez. É isso. Só pode ser" (Mutarelli, 2002, p. 29).

A associação entre o estado psicológico da personagem e o cheiro do ralo ganha uma dimensão concreta no diálogo com um cliente que lhe quer vender um violino. Mal tratado, o cliente vinga-se estabelecendo às claras a associação que percorre em surdina toda a narrativa:

Ele pega o violino e sai.

Mas antes de fechar a porta, solta:

Aqui cheira a merda.

É o ralo.

Não. Não é não.

Claro que é. O cheiro vem do ralo.

Ele entra e fecha a porta.

$\mathrm{O}$ cheiro vem de você.

Olha lá. Levanto e caminho até o banheirinho.

Olha lá, o cheiro vem do ralinho.

Ele ri coçando a barba.

Quem usa esse banheiro?

Eu.

Quem mais?

Só eu.

Ele continua com o sorriso no rosto, solta:

E então, de onde vem o cheiro? (Mutarelli, 2002, p. 16-17).

No romance $A$ arte de produzir efeito sem causa, a personagem Júnior passa por uma série de revezes em sua vida pessoal; traído pela mulher com o filho adolescente de seu chefe, ele abandona o emprego e passa a morar de favor na casa do pai. Como já observamos antes, é recorrente que as personagens de Mutarelli vivam em apartamentos apertados no subúrbio. No caso, trata-se de um apartamento pequeno, com um único quarto (dividido por uma divisória em duas partes, sendo que uma delas é alugada para uma estudante pelo pai de Júnior), cabendo ao nosso 
protagonista dormir no sofá da sala: “O sofá é pequeno e malcheiroso [...] Os lençóis cheiram a naftalina, a almofada foi impermeabilizada por uma camada de gordura humana" (Mutarelli, 2008, p. 15-16). É nesse ambiente tacanho que se desenrolarão os principais fatos do enredo, cuja linha de força principal é o progressivo adoecimento de Júnior.

Como em outros romances do autor, também no ambiente doméstico, fechado, o protagonista não encontra a proteção pretendida. Ao invés, nesse espaço da intimidade ele é o tempo todo golpeado por dissabores diversos. Observe-se inicialmente que no espaço externo a situação é assustadora: o mundo mostra-se extremamente hostil. É um mundo atravessado por imposições de comportamento e apelos ao consumo: "A máxima dos nossos dias: o importante é morrer com saúde" (Mutarelli, 2008, p. 42); “Júnior apanha um pedaço de pão no saco pardo que agradece a preferência" (p. 18); "No caminho de volta para a casa do pai, encontra a loja que veste um homem da cabeça aos pés" (p. 33). Desempregado, sem dinheiro, traído pela mulher - em suma, o perfil acabado de um perdedor - como pode Júnior afirmar-se nesse ambiente atravessado pelas exigências do capital?

Não por acaso, a única cena em que Júnior por assim dizer levanta a cabeça é quando recebe mil e trezentos reais como último salário de seu antigo emprego. O dinheiro, ainda que pouco, opera uma transformação radical na sorumbática personagem: "Até sua postura muda. Ele parece crescer uns centímetros, em todos os sentidos". Mais que isso, mil e trezentos reais permitem que ele volte a sentir-se parte da sociedade: "Precisa gastar o dinheiro para sentir que voltou a fazer parte da sociedade. Integrar-se". Com efeito, compra sapatos e sai "carregando com orgulho a sacola" (Mutarelli, 2008, p. 114). A passagem ilustra à perfeição, a nosso ver, a constatação de Maria Rita Kehl, anteriormente citada, de que na atualidade o sentido da vida social e o próprio valor dos sujeitos - no limite, a sua identidade - são dadas pelo consumo.

Pode-se observar que Júnior - e isso se agrava com o seu adoecimento mental progressivo - está perdendo a corrida dos vencedores: “Júnior perde gradualmente o vínculo com o tempo social" (Mutarelli, 2008, p. 130). O tempo social é acelerado, e Júnior torna-se cada vez mais lento, mais inseguro, mais inadaptado. Com o passar do tempo, começa a cogitar em um projeto de vida que converta sua lentidão em paralisia plena: "Uma ideia vem ocupando sua mente. Será que ele realmente precisa voltar a trabalhar? Por que não ir levando, empurrando? Enrolando o pai. Onde come um comem dois" (p. 102).

No apartamento minúsculo que divide com o pai, Júnior começa a receber estranhos pacotes pelo correio: remetente ignorado e conteúdo es- 
tranhíssimo, que mais tarde se descobrirá estar relacionado com o escritor Wiliam Burroughs e à morte de sua esposa em um acidente com pistola. Boa parte da energia mental da personagem será gasta para decifrar essas mensagens estranhas. Bachelard já observou que cofres, caixas, armários e congêneres têm a ver com a "psicologia do segredo"; caixas também podem ser remetidas ao "caráter fechado" de algumas pessoas (Bachelard, 1993, p. 94-95). Em A arte de produzir efeito sem causa, as caixas chegam com um segredo de consequências nefastas, pois perturbam a personagem, agravando seu estado mórbido, atravessado por quadros de convulsão e perda gradativa das faculdades linguísticas.

É notório que em Mutarelli esses espaços fechados, pequenos, apertados e muitas vezes claustrofóbicos - sejam eles um apartamento ou uma caixa - estão intimamente relacionados ao caráter fechado de suas personagens, à timidez, ao sentimento de fracasso, ao ensimesmamento doentio, ao remoer contínuo das pequenas tragédias cotidianas. Suas personagens buscam proteger-se nesses ambientes reclusos, mas acabam sempre frustradas em suas intenções.

No romance Jesus Kid há um pequeno diferencial. O protagonista aceita por conta própria isolar-se em um quarto de hotel durante três meses em razão de um contrato de trabalho. Eugênio, escritor de sucesso de westerns de bolso (livros de aventuras vendidos em bancas de jornais), recebe a proposta de dois agentes do cinema para elaborar um roteiro sobre a história de um escritor em seu processo criativo, suas dificuldades e as dores da criação. Para fazê-lo, Eugênio deve ficar totalmente isolado em um quarto de hotel, sem jamais poder sair à rua durante esse período.

A situação extravagante serve a Mutarelli para estabelecer uma crítica feroz, embora bem-humorada, à mercantilização da arte na sociedade contemporânea. Seja referindo-se ao cinema, seja à própria literatura, o que está em jogo aqui é a prostituição do artista no mercado de bens culturais. Em seu momento de reflexão mais aguda e dolorosa, Eugênio dá-se conta de que seu papel é, em fim de contas, produzir divertimento barato para alienação das massas consumidoras: "Como uma puta, uma cadela, alugo meu cérebro para que lhe enfiem ideias e eu as transforme em prazer, ou entretenimento. Como uma puta, cadela, devo dar-lhes ação. Devo diverti-los e fazer o tempo passar" (Mutarelli, 2004, p. 103). Em outro momento, sempre trancado no quarto, vê-se como um escritor de histórias "que entretenham e divirtam comedores de pipocas em salas de projeção" (p. 108).

Consideradas suas reflexões sobre a função social da arte na sociedade de consumo como linha de força principal do romance, vale a pena insistir 
na utilização de espaços fechados como elementos detonadores da angústia existencial da personagem (lembrando-se, aliás, que etimologicamente a palavra "angústia" remete às noções de estreitamento e aperto). Preso no quarto, Eugênio recebe suas refeições sob encomenda de um restaurante chinês. Abrindo as caixas de alimento ele se depara com o típico biscoitinho da sorte, que sempre lhe traz notícias preocupantes. Aparentemente, alguém trancafiado em algum lugar se vale dos biscoitinhos para pedir socorro ao encarcerado Eugênio:

Parto o biscoitinho da sorte:

"Me ajude, estou preso!"

Nunca entendo essas frases. Minha úlcera desperta furiosa. Náuseas. Desconforto. Acho que estou tendo uma congestão. Sinto minha boca entortar (Mutarelli, 2004, p. 56).

Como se nota, a situação descrita lembra em tudo aquela de $A$ arte de produzir efeito sem causa, em que as caixinhas recebidas por Júnior pelo correio irão contribuir decisivamente para sua perturbação e adoecimento. Dentro de quartos-caixas surgem outras caixas com signos perigosos... Como já observado, trata-se de espaços que, ao invés de servirem como refúgio protetor, acabam tornando-se outro motivo de opressão para as personagens. Bem a propósito, leia-se como Eugênio descreve seu quarto do hotel: "Volto, exausto, para o quarto [...]. O quarto fede à comida chinesa em decomposição avançada. A janela, emperrada. Respiro o ar falso. Sinto o terror de um novo derrame e a falta de ar causada por uma enfisema pulmonar" (Mutarelli, 2004, p. 137).

Dada sua recorrência nos romances de Mutarelli, pode-se afirmar que o agenciamento de espaços fechados é parte estrutural de suas histórias. Esses locais compõem um cenário deprimente que se ajusta perfeitamente às personagens que encerram, muitas delas esmagadas pelo peso do fracasso profissional e afetivo, desajustas em relação ao meio social em que vivem e, via de regra, em demanda de algum tipo de proteção - de uma caixa-útero que lhes possa servir de abrigo.

A esta altura, e lembrando que Mutarelli é sabidamente um extraordinário quadrinista, cumpre notar que o trabalho com espaços fechados já é uma marca forte de sua produção em quadrinhos, a qual antecede sua estreia como romancista. Não nos parece equivocado sugerir que, nesse caso, o Mutarelli quadrinista exerce forte influência sobre o trabalho do Mutarelli romancista. Observe-se, nessa linha de argumentação, o exemplo desta notável página de $\mathrm{O}$ rei do ponto, aqui apresentada apenas em parte, na qual vemos o detetive Diomedes lamentando-se de seus infortúnios: 


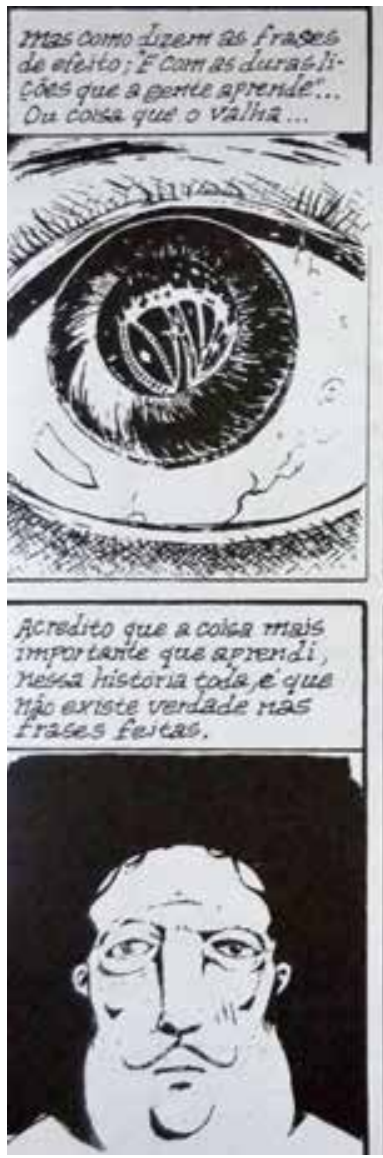

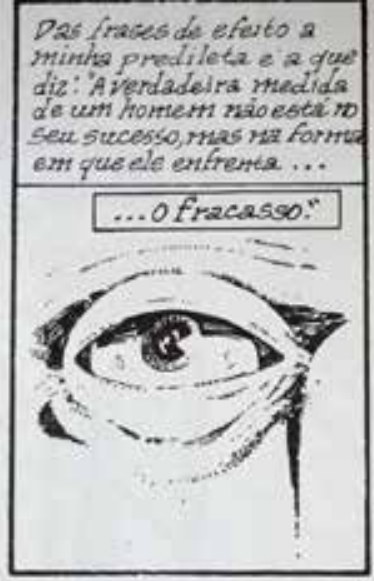

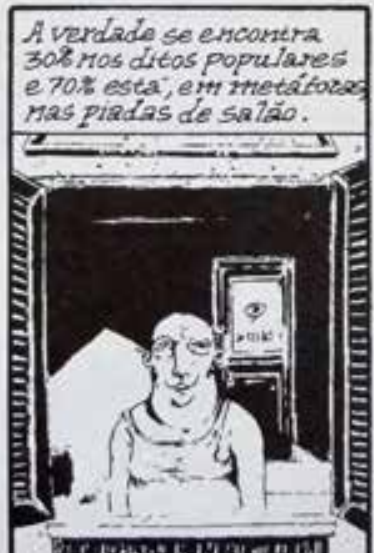

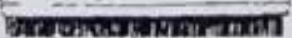

Como dinian as americanos a menos of dos filmes, I $\mathrm{ra}$. casso, esse e o meu nome.

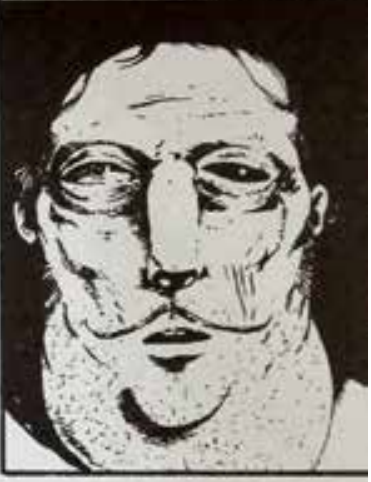

Pode acreditar nisso, mee Eilto.

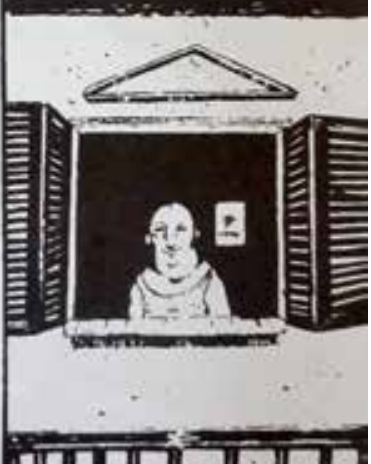

Fonte: Mutarelli (2000, p. 8). 
O detetive Diomedes situa-se na contramão dos grandes detetives da literatura policial tradicional: ele não é bonito ou conquistador, vive com muitas dificuldades financeiras, a mulher o trai com vários outros homens, ele não consegue resolver os casos que investiga... "Fracasso, esse é meu nome". Do ponto de vista da utilização gráfica do espaço, cumpre notar que há uma progressão que acompanha o desfile de lamúrias do detive. Conforme ele vai confessando seu fracasso, o espaço vai mais e mais se estreitando, enclausurando-o... Como nos romances considerados, ocorre uma convergência entre estados psicológicos depressivos e confinamento espacial. A sequência dos quadrinhos parte de um "plano geral" (no primeiro quadrinho vemos a paisagem externa - que aparecera nos desenhos precedentes - refletida no olho de Diomedes) e progressivamente vai se afunilando, até situar, no último deles, a personagem em um quarto minúsculo.

Mas é sem dúvida nenhuma o romance $O$ natimorto o ponto culminante das relações entre estados psíquicos patológicos e espaços claustrofóbicos. Por isso concluímos com ele. Nessa narrativa um agente convida uma cantora (referida como "A Voz") para morar com ele em um quarto de hotel por vários anos. Segundo o agente, fechados e isolados ambos ficariam a salvo das maldades e agressividades da sociedade. Citamos a seguir a passagem em que o agente faz a proposta à cantora:

O Agente - Eu não suporto mais ser agredido.

O Agente - Então eu te proponho isso.

A Voz - Isso o quê?

O Agente - Bom, com as economias que eu tenho, nós poderíamos viver aqui neste quarto de hotel por uns cinco ou seis anos.

A Voz - Meu Deus!

O Agente - E veja bem: isso sem nunca precisarmos sair daqui.

O Agente - E ainda existe a chance de que por fim nos esqueçam aqui, aí então viveríamos aqui pelo resto de nossas vidas... protegidos...

$[\ldots]$

O Agente - Eu tenho tantas ideias. Eu tenho tantas histórias.

O Agente - Eu poderia distraí-la contando-as a você.

O Agente - E você cantaria para mim.

O Agente - E nós cuidaríamos um do outro.

[...]

O Agente - Você não iria se machucar nunca mais.

O Agente - Eu cuidaria de você com tanto carinho (Mutarelli, 2009, p. 32-33)

A cantora chega a levar em consideração a proposta do agente, dado o momento difícil que atravessa, mas logo se dá conta da impossibilidade de uma existência entre quatro paredes. Enquanto o agente passa o tempo 
todo no quarto de hotel, ela sai à rua para resolver seus assuntos, retornando frequentemente ao quarto e ao contato com a personagem masculina. Neste diálogo entre os dois aparece a palavra "claustrofobia":

A Voz - Não sei como você consegue ficar aqui trancado.

O Agente - E eu não sei como você consegue ficar lá fora solta.

[...]

A Voz - Sabe que eu estou quase desenvolvendo uma claustrofobia. A Agente - Sério?

A Voz: É, só de ver você trancado aqui, sem sair para nada. Isso me dá uma agonia (Mutarelli, 2009, p. 81).

As personagens de Mutarelli buscam abrigar-se em lugares fechados para se protegerem das ameaças dos contatos sociais. $\mathrm{O}$ agente de $\mathrm{O}$ natimorto tem o hábito de ler a sorte e o destino nas imagens dos maços de cigarro, como se tais imagens fossem cartas de tarô. Uma das imagens dos maços é justamente a do "natimorto", o da criança que nasce morta por influência do tabagismo da mãe. Trata-se de uma imagem aterrorizante, que faz parte da campanha contra o cigarro, na linha "o Ministério da Saúde adverte que fumar é prejudicial à saúde". Curiosamente, entretanto, o agente faz uma interpretação extremamente positiva dessa imagem. Segundo ele, o natimorto "representa a vida vencendo qualquer obstáculo":

O Agente - Mesmo que um bebê nasça morto, nós consideramos o seu nascimento.

A Voz - Mas ele não viveu.

O Agente - Viveu uma vida intrauterina. Para morrer, é preciso viver. A Voz - Mas isso é horrível, é triste.

O Agente - Isso é sublime. Ele tornou mãe a mulher que o pariu. E ela sempre dirá: meu filho "nasceu" morto. Isso o torna um ser superior, quase um santo. Viveu sem macular-se com o mundo. Pulou uma passagem de sofrimento e desilusão. Foi da não existência a não existência protegido no interior de sua mãe. Puro (Mutarelli, 2009, p. 80).

A passagem citada diz respeito tanto ao ideal de "pureza" humana almejada pela personagem de modo completamente doentio quanto à aludida vontade de regressar ao útero materno em busca de proteção. Como em outros romances de Mutarelli, a proteção não é alcançada; ao invés, o quarto fechado torna-se um espaço opressivo, que contribui para o gradativo enlouquecimento da personagem. O agente vai se tornando cada vez mais depressivo, sofre de convulsões e por fim - exatamente como ocorre com o Júnior de $A$ arte de produzir efeito sem causa - elabora um plano de assassinato. Sua intenção passa ser a de comer, literalmente, a cantora: "Ela pesa em torno de sessenta quilos, no máximo. Se eu conseguir comer cinco quilos de carne por dia, seis vezes cinco, trinta, em menos de dez dias não sobrará nada" (p. 122). 
O assassinato seria uma vingança do agente, que se sente também abandonado pela cantora, a quem propusera uma vida de proteção e cuidado recíprocos no quarto. Diz ele: "Ninguém mais vai me ferir com olhares ou palavras. Ou com descaso" (Mutarelli, 2009, p. 126-127). A tentativa de dar as costas à sociedade e refugiar-se em algum lugar fechado, isolado, sempre acaba em redundante fracasso ou delírio assassino nos romances de Mutarelli. Assim sendo, o escritor parece nos sugerir que a demonização do Outro não é solução para os conflitos pessoais. Não é possível salvar-se simplesmente procurando afastar todo contato social.

Como na história que o agente narra à cantora - que tem a dimensão de uma quase parábola - o inimigo pode estar mais próximo do que se supõe. Trata-se da história do poço que ficava no quintal da avó - outro lugar fechado, apertado, angustiante, claustrofóbico! Quando criança, o agente e um primo ouviam do tio que no poço havia um monstro, bem no fundo. Era uma tentativa para manter os meninos longe do perigo. Entretanto, o primo do agente um dia cai no poço (na verdade, quem cai no poço é o próprio agente, como se descobre ao final do romance). Por sorte, havia um pouco de água no fundo do poço, o que amorteceu a queda do primo (o próprio agente). Leia-se o desfecho:

O Agente - Mas, ao mesmo tempo, com a luz que entrava no buraco e incidia na água, ele acabou vendo o seu próprio reflexo.

O Agente - Por fim, quando o içaram, eu corri e perguntei a ele: " $\mathrm{E}$ então, como é o monstro?".

O Agente - E a resposta foi: "Ele é como nós. Todos somos monstros" (Mutarelli, 2009, p. 26-27).

\section{Referências}

BROMBERT, Victor (2001). Em louvor de anti-heróis. São Paulo: Ateliê.

BACHELARD, Gaston (1993). A poética do espaço. Tradução de Antonio de Pádua Danesi. São Paulo: Martins Fontes.

KEHL, Maria Rita (2009). O tempo e o cão: a atualidade das depressões. São Paulo: Boitempo.

MUTARELLI, Lourenço (2000). O rei do ponto. São Paulo: Devir. (2002). O cheiro do ralo. São Paulo: Devir. (2004). Jesus Kid. São Paulo: Devir. (2008). A arte de produzir efeito sem causa. São Paulo: Companhia das Letras. (2009). O natimorto. São Paulo: Companhia das Letras.

Recebido em dezembro de 2012. Aprovado em abril de 2013. 


\section{resumo/abstract}

\section{Espaços claustrofóbicos na obra de Lourenço Mutarelli}

Pascoal Farinaccio

O artigo propõe a existência de relações entre estados psicológicos depressivos e espaços claustrofóbicos na obra literária de Lourenço Mutarelli; nessa perspectiva, analisa passagens de romances do autor para indicar a tematização e a recorrência das relações sugeridas e suas possíveis significações.

Palavras-chave: Lourenço Mutarelli, literatura brasileira contemporânea, espaços claustrofóbicos.

\section{Claustrophobic spaces in the work of Lourenço Mutarelli}

Pascoal Farinaccio

This paper proposes the existence of relations between psychological states of depression and claustrophobic spaces in the literary work of Lourenço Mutarelli; in this perspective, it analyses passages from the novels by the author to indicate the thematization and recurrence of these suggested relations and its possible meanings.

Keywords: Lourenço Mutarelli, contemporary Brazilian literature, claustrophobic spaces. 